\title{
A PERSISTÊNCIA DA VOZ POÉTICA DE STELA DO PATROCÍNIO: ENTRE A ORALIDADE E A ESCRITA
}

The persistence of Stela do Patrocínio's poetic voice: between orality and writing

\section{Marianna Ilgenfritz Daudt}

https://orcid.org/0000-0001-9485-2316

\section{Fernanda Vivacqua}

(iD) https://orcid.org/0000-0002-5425-3631

Universidade Federal do Rio Grande do Sul, Programa de Pós-Graduação em Letras, Porto Alegre, RS, Brasil. 91501-970 - ppglet@ufrgs.br

Resumo: Este artigo tem como objetivo apresentar uma leitura de Reino dos bichos e dos animais é o meu nome (DO PATROCÍNIO, 2001), obra com a produção poética oral de Stela do Patrocínio e transcrita por Viviane Mosé. Percebida a colocação de uma voz poética viva nos poemas, nosso interesse primeiro foi discutir como esta se desloca da oralidade para a escrita. Para tanto, analisamos a poética de Stela do Patrocínio a partir de dois vieses. Por um lado, nosso interesse centrou-se em como a questão da autoria é refratada, ao transpor a poética para a poesia escrita. Por outro, voltamo-nos para a relação do leitor com esta voz poética, entendendo os dois em suas dimensões corpóreas, e ocupando lugares no espaço. Para tanto, recorremos às contribuições principalmente de Foucault (2009, 2011), Gumbrecht (2010) e Zumthor (2014). Em meio ao debate, evidencia-se a voz poética nos versos, uma vez que, ao fazer uma leitura crítica destes, é igualmente necessário que eles sejam vocalizados. Por fim, através do percurso teórico e crítico, acreditamos que, transposta para a escrita, a voz poética de Stela do Patrocínio (2001) segue pulsando no leitor, em uma dinâmica em que a tensão se altera, mas a produção de presença permanece.

Palavras-chave: Stela do Patrocínio. Produção de presença. Poesia contemporânea. Oralidade. Escrita.

Abstract: The present study aims to present a view on Stela do Patrocínio's oeuvre Reino dos bichos e dos animais é o meu nome [Kingdom of beasts and animals is my name] (DO PATROCÍNIO, 2001), a work that was poetically produced orally by Stela do Patrocínio and transcribed by Viviane Mosé. In our research, we consider that there is a living poetic voice in poems, and our first interest was to discuss how it moves from orality to the writing form. For this purpose, we analyzed Stela do Patrocínio's poetics from two approaches. On the one hand, our interest was centered on the way in which how the question of authorship is refracted, when

Esta obra está licenciada sob uma Creative Commons - Atribuição 4.0 
transposing poetics to written poetry. On the other hand, we turn to the reader's relationship with this poetic voice, understanding the two in their bodily dimensions, taking in account their places in space. For that, we used the theoretical propositions mainly by Foucault $(2002,2009)$, Gumbrecht (2010) and Zumthor (2014). Amid the debate, the poetic voice is evident in the verses, since, when making a critical reading of these, it is also necessary that they be vocalized. Finally, through the theoretical and critical path, we believe that, transposed to writing, the poetic voice of Stela do Patrocínio (2001) continues to pulse in the reader, in a dynamic where the tension changes, but the production of presence remains.

Keywords: Stela do Patrocínio. Presence production. Contemporary poetry. Orality. Writing.

\title{
Introdução
}

\author{
[…] \\ Pelo espaço vazio você também não vai poder ficar \\ Porque lugar de cabeça é na cabeça \\ Lugar de corpo é no corpo (DO PATROCÍNIO, 2001, p. 52).
}

Com este artigo, pretendemos realizar uma análise da voz poética presente de Reino dos bichos e dos animais é o meu nome, de Stela do Patrocínio (2001). Além das especificidades próprias da palavra poética, a obra carrega singularidades que fizeram com que voltássemos nosso olhar para ela, e, por isso, queremos, neste primeiro momento, apresentar a autora e o contexto de feitura do livro. Como conta Ricardo Aquino (2001), então diretor do Museu do Bispo do Rosário, a trajetória de Stela do Patrocínio foi marcada pela vida em hospitais psiquiátricos, o que se iniciou em 1962, com sua primeira internação no Centro Psiquiátrico Pedro II, e sendo posteriormente, em 1966, transferida para a Colônia Juliano Moreira, como era chamada à época. Passados mais de trinta anos nesse hospital, Stela faleceu em 1992, nas dependências da Colônia. Sendo assim, sua biografia se entrelaça com a história da reforma psiquiátrica brasileira, partindo de um contexto de extrema violência, mas também passando por um outro momento, com novas abordagens, tais como as psicoterapias envolvendo as artes plásticas e a palavra. Foram através dessas práticas que as falas, ou o falatório, de Stela do Patrocínio foram gravadas em fitas cassete, entre os anos de 1986 e 1989. Em 1998, o Museu do Bispo do Rosário realizou a exposição “Ar subterrâneo”, no Paço Imperial do Rio de Janeiro, onde foram expostas diversas produções feitas em oficinas artísticas com os internos, e, dentre eles, estava o trabalho de Stela. Disso, derivaram algumas criações artísticas, como o uso de frases da autora em shows musicais e, já no nosso século, em 2001, a montagem, para o teatro, de um monólogo, como uma adaptação do material de Stela do Patrocínio.

Esta última só foi possível pelo resgate realizado por Viviane Mosé, que foi trabalhar no Museu do Bispo do Rosário para realizar oficinas de escrita com os internos e pesquisa. Nesta ocasião, a pesquisadora entrou em contato com as gravações de décadas anteriores e, absorta com a tensão poética encontrada nos falatórios de Do Patrocínio, acabou por mudar os rumos de seu trabalho no local, passando a debruçar-se sobre a poética encontrada, para transcrever sua fala para o registro da poesia escrita: 
de um outro tipo de texto. A diferença em relação ao que já conhecia de outros pacientes era explícita. O que vinha percebendo, na maioria dos textos que chegavam a mim desde que comecei o trabalho, era que, em geral, quando um interno buscava se manifestar pela palavra, isto se fazia na direção da interioridade e da subjetividade [...]. Com Stela era diferente, ela parecia capaz de se organizar neste limite, nesta tensão entre ordem e ausência de ordem. Sua palavra é capaz de se manter sem se sustentar, necessariamente, nos limites subjetivos, gramaticais e lógicos, ou seja, não é exatamente este tipo de ordenação que sua linguagem ou seu psiquismo buscava. Ousaria dizer que Stela se sustentava em uma ordenação delirante, uma ordenação móvel, fundada na afirmação de sua própria fragmentação (MOSÉ, 2001, p. 23-24).

No excerto acima, Viviane Mosé (2001) explica ao leitor como, iniciado seu trabalho no Museu, as gravações do falatório de Stela a fizeram mudar o foco de sua investigação, uma vez que ela se deparou com uma relação com a palavra que transpunha os limites de um falar de si, através de uma subjetividade descentrada. Mosé (2001) afirma compreender como esse elemento se configura como uma marca recorrente nas escritas de pessoas com passagens psiquiátricas, mas, no caso de Stela, a tensão entre tal subjetivismo e uma forma de ordenação produziram uma poética que ultrapassa qualquer definição de simples delírio, ou reflexo de um mundo interior. Sem deixar de ser, portanto, uma poética pensada pelo viés do espaço hospitalar, e da realidade psiquiátrica, a poética de Stela do Patrocínio ultrapassaria esses limites. Ademais, a pesquisadora (MOSÉ, 2001) ainda explica que, apesar de não haver muitos impasses gramaticais ou sintáticos, a transposição da oralidade para a escrita traz, intrinsecamente, distinções, ou, nas suas palavras, "hiatos" (MOSÉ, 2001, p. 26) ${ }^{1}$. Estes hiatos, por conseguinte, ocorreriam por dois motivos. O primeiro refere-se ao trabalho de selecionar quais textos seriam transpostos para a escrita e como o livro seria organizado, o que levou Mosé a, após ouvir repetidas vezes as fitas cassete, aglutinar os textos em partes, por temáticas que se aproximassem - como o hospital e a casa, como espaços em mescla, e os corpos em meio a formas gasosas. O segundo motivo, por outro lado, recai sobre as descontinuidades entre a oralidade e a escrita em geral, por cada uma trazer, em seu bojo, questões e debates próprios.

Fizemos esse percurso para chegar a este ponto, que é de onde se inicia o nosso trabalho. Sendo a voz uma marca na poética de Stela do Patrocínio (2001), desejamos refletir sobre como

\footnotetext{
${ }^{1}$ Destaca-se, portanto, o caráter editorial do projeto. Isto é, todo livro de poesia, mais que um conjunto de poemas, é um projeto editorial que passa por diferentes sujeitos, partindo do autor, enquanto sujeito biográfico, até chegar ao leitor. No caso de Reino dos bichos e dos animais é meu nome (DO PATROCÍNIO, 2001), ademais, este caráter se complexifica, tendo em vista que o projeto não emerge de uma vontade consciente de Stela do Patrocínio. Pelo contrário, o nó se dá justamente pelo entrecruzamento de procedimentos que, dela, independem - como a transcrição de seu falatório e sua versificação, mas também a seleção e a modificação de trechos, além dos elementos editoriais em si. Por isso, um desdobramento futuro possível, em tudo rico, seria uma análise comparada das gravações in loco e do livro, editado e impresso. Com isso, chega-se ao impasse sobre considerar o falatório, em si, como poesia. Este entrave, contudo, leva a um sem par de questões que o tangenciam, como a própria conceituação de poesia e a atribuição de literalidade a textos não literários. Infelizmente, não temos como prolongar a discussão neste espaço. Ainda assim, acreditamos que, independente do debate em torno do falatório ser ou não poesia, é importante termos no horizonte a noção de a produção oral de Stela do Patrocínio como algo que se conforma como poético (ZUMTHOR, 2014), na medida em que - como falaremos adiante (nota de rodapé n. 3) - afeta este corpo que o ouve - no caso, o de Viviane Mosé, que atesta ter percebido a singularidade no discurso de Stela.
}

Anu. Lit., Florianópolis, v. 25, n. 2, p. 28-46, 2020. ISSNe 2175-7917 
essa voz se envolve, e se desloca, no mundo da palavra escrita. Isto é, dado que a força e a tensão (MOSÉ, 2001) da poética de Stela é percebida pela oralidade, por quem a gravou e por Mosé (2001), entendemos que seja pertinente questionar quais os desdobramentos desta transposição da oralidade para a escrita. Para tanto, acreditamos que o debate possa ser feito por duas pontas: por meio da discussão em torno da autoria, e de como a passagem da oralidade para a escrita nela interfere; e pela relação do leitor, como corpo experienciando a palavra poética, com esta voz poética - em sua capacidade de se fazer presente. Sabemos que estas abordagens não encerram a discussão, e não poderia ser diferente. A leitura crítica de poesia se abre, cada vez mais, para um sem fim de possibilidades. Ainda assim, acreditamos que desenvolver estes dois prismas para se olhar para a persistência da voz poética de Stela do Patrocínio, na transposição de seu falatório para a escrita, pode nos auxiliar na reflexão. Para tanto, traremos as vozes de outros autores teóricos, tais como Foucault (2011), acerca da noção de autoria, Gumbrecht (2010), com seu conceito de "produção de presença", e Zumthor (2014), com suas ideias sobre o corpo do leitor na experiência poética.

Mas, para além de tudo isso, o que esperamos que emerja é a voz poética de Stela do Patrocínio. É ela que, como escafandristas em meio à palavra escrita, queremos encontrar. Este desejo, por sua feita, não nasceu do vazio: são os poemas de Reino dos bichos e dos animais é o meu nome (DO PATROCÍNIO, 2001) que nos fizeram ouvir essa voz, pelos ruídos da escrita, e querer persegui-la:

Eu vim do Pronto Socorro do Rio de Janeiro

Onde a alimentação era eletrochoque, injeção e remédio

E era um banho de chuveiro, uma bandeja de alimentação

A viagem sem eu saber pra onde ia

Vim parar aqui nessa obra, nessa construção nova (DO PATROCÍNIO, 2001, p. 53).

Terminamos esta breve apresentação com o poema acima, pela intensidade que o mesmo remete, ao apontar para um ponto de onde se veio e outro, onde se vai parar. A tensão entre a experiência psiquiátrica, marcada por signos que se consubstanciam na própria experiência ("E era um banho de chuveiro, uma bandeja de alimentação"), e o novo, uma construção que é obra, e para onde se vai parar sem saber direito como. Uma oscilação imprecisa entre estados que coloca este "eu", a voz poética, em cena, afirmando-se em sua presença. A voz poética de Stela do Patrocínio (2001) se afirma, a todo momento, em um espaço, vagando entre o hospital e a casa, a obra e a construção, e - por que não? - a própria linguagem, sempre nova em suas possibilidades, apesar de sua estrutura, mais edificadora que edificante. Dito isso, antes de iniciarmos de vez a leitura desta poética, gostaríamos de explicitar que não é nosso objetivo um texto com uma análise ancorada na vida psiquiátrica de Stela do Patrocínio, posto que nosso interesse não recai sobre uma questão hermenêutica. Por outra mirada, pretendemos nos deter na relação entre a oralidade e a escrita, na produção dessa voz, entendendo que, independente das apreensões biográficas, que também nos afetam, como leitoras, o que queremos, aqui, é trazer à baila é a poética de Stela do Patrocínio em si - em seu emaranhado único, ancorado na 
linguagem -, e não tanto as condições que a propiciaram.

Em um primeiro momento de desenvolvimento teórico, busca-se partir do movimento de "transposição" da voz à escrita, conforme termo da própria organizadora sobre seu trabalho na introdução do livro, para desenvolver uma discussão acerca da frágil noção de autoria que se assenta nas ideias de uma suposta estabilidade de relações entre os corpos e a vozes e entre a voz e a escrita. Abordam-se, a seguir, as noções de presença e ausência no texto e no sentido que se constrói a partir deste, bem como se examinam algumas definições dos sujeitos envolvidos neste produto de diferentes vozes autorais. De um prisma linguístico, analisam-se passagens contidas nos poemas de Stela do Patrocínio (2001) com objetivo de mostrar a forma que ela própria compreendia sua posição enquanto sujeito e enquanto poeta dentro das possibilidades oferecidas em seu contexto social.

\section{A escrita entre identidade e enunciação}

Na apresentação de Reino dos bichos e dos animais é o meu nome (DO PATROCÍNIO, 2001) é possível conhecer a história de Stela do Patrocínio e o formato primeiro em que a obra chega aos ouvidos de Viviane Mosé (2001). Sabe-se, assim, que seus procedimentos de escrita partem da observação da performance oral de Stela, sendo este o foco do projeto artístico de Mosé, que busca construir um texto marcado pelo tom da poesia gravada na voz de sua enunciadora primeira. Vê-se, no entanto, os vestígios de escrita da poeta Viviane. Desse modo, a obra permite ao leitor entrar em um universo poético de múltiplas camadas e atravessar diversas instâncias de movimentos psicológicos, por meio dos deslocamentos de enunciação, de leitura, de escrita e de releitura que foram feitos para tornar os fragmentos de textualização oral uma composição poética de visualização gráfica. O texto que circunscreve a obra é um eco, é um corpo escrito que empresta sua materialidade à voz que o guia, originada em algum lugar da linguagem de um outro corpo, este mesmo atado unicamente ao ressoar de sua própria criação.

Devido à condição de Stela, não seria possível afirmar que há uma intenção poética clara de sua parte, porém seria também contraditório com relação ao aporte teórico utilizado no presente texto afirmar que seus falatórios seriam fruto apenas de um tratamento ou de um estado psiquiátrico proscrito pelas camadas consideradas sãs da sociedade. Para além da incongruência de se buscar discutir o grau de autoconsciência das falas de Stela, some-se o fato de que o desenvolvimento de nossa argumentação se dá no sentido justamente de mostrar a delicadeza e a complexidade dos movimentos referentes à produção de presença na arte literária, mais especificamente na poesia. Nesse sentido, aproximamo-nos das proposições de Barthes (2004), Foucault (2009; 2011), Gumbrecht (2010), Zumthor (2014) de que não seria a presença da autora em si - sua fala ou seu contexto de fala - o que propiciaria a produção do valor estético, mas a ausência, a abstração produzida pelo produto escrito. No caso das poesias de Patrocínio/Mosé, podemos problematizar tal questão em dois momentos, pois é possível encontrar um espaço de ausência - uma lacuna de sentido que possibilitará à voz poética, uma voz de natureza não material, mas experiencial, inscrever-se no próprio espaço dos poemas -

Anu. Lit., Florianópolis, v. 25, n. 2, p. 28-46, 2020. ISSNe 2175-7917 
primeiro na passagem do falatório de Stela para a escrita de Viviane, e um espaço (talvez ainda mais fundamental) na passagem de seu resultado para a interpretação sempre particular e mutável de cada um dos leitores. Desse modo, compreendemos que as intenções de um autor, bem como suas circunstâncias de escrita, fazem parte do contexto da escritura, porém esses fatores não impõem limites reais ao significado do texto nem, tampouco, ao valor poético desse texto, pois o significado da linguagem jaz na ausência e não na presença, ou em outra palavras, antes de exigir uma consciência, requer o seu apagamento.

O trabalho de Viviane, portanto, permite ao universo de leitores, ao qual se dirige, um trabalho de investigação e de reflexão, um lugar para pensar na relação da voz com a escrita, no sentido de demonstrar que as realidades acústicas podem ser independentes das sistematicidades sintáticas e semânticas escritas, pois a voz que se materializa no fazer autoral de Viviane não é a mesma de Stela. Ouvir Stela não é o mesmo que ler Viviane, porém, tratase de uma autoria na qual se encontra uma voz na construção do sujeito (e) da linguagem e, também, lê-se um corpo de escrita atravessado pela voz.

Viviane Mosé (2001) relata, em sua introdução, que a fala de Stela era fluida, de modo que foi possível sentir o ritmo e o separar em versos, e que continha poucos desvios da norma padrão, sendo que correções quase não foram necessárias. Além disso, ressalta que os textos são constituídos de trechos corridos, ou seja, sem recortes ou colagens. Porém, de seu punho ainda são as preocupações com as pausas, a seleção dos textos e as alterações poéticas como a substituição de formas orais "tô" e "tive" pelos correspondentes "estou" e "estive", por exemplo, mais alinhados à forma escrita. Em verdade, o trabalho manual de Viviane com a voz de Stela se assemelha, em diferentes medidas, com o trabalho de um autor que escreve sua própria voz. A escrita pode tão pouco restituir a voz primeira de seu autor primeiro quanto o poderia fazer o texto de Viviane a nós, leitores de Stela. Tudo o que se tem na leitura de qualquer texto é apenas a própria leitura, do contrário seria necessária a pressuposição de que existe um sentido fixo incontestável atribuído metafisicamente a cada significante de um texto. Por isso, a escrita é sempre o espaço de um sujeito fluido, um autor que surge ao desaparecer.

Em termos de literatura, Foucault (2009) já explica que, por muito tempo, a razão ocidental ignorou a experiência de uma linguagem da qual o sujeito está excluído, a revelação de uma incompatibilidade talvez irremediável entre a aparição da linguagem em seu ser e a consciência de si em sua identidade, uma abertura que hoje ganha campo desde a literatura até a psicanálise. De acordo com o autor, "o ser da linguagem só aparece para si mesmo com o desaparecimento do sujeito" (FOUCAULT, 2009, p. 222), um sujeito que se diluirá na experiência da escrita para emergir anônimo no limite fluido e infinito em que as definições fixas se perdem no limite da presença.

Os jogos entre presença e ausência que se originam do processo de escrita de Reino dos bichos e dos animais é o meu nome (DO PATROCÍNIO, 2001) estão em consonância com as teorias que se opõem às logicas binárias, no que tange tanto à construção de um indivíduo como à construção de um texto, dado que, ainda que a escrita esteja atada a uma estrutura de fala, não há um sujeito centrado (humanista), ou tampouco um sujeito a fazer o caminho previsto 
estrutural(ística)mente em sua proposta enunciativa, revelando-se antes uma escrita que se volta, enquanto reflexão, ao discurso originário. Segundo Nodari (2017),

a metafísica ocidental privilegiou o escrito como signo frente ao fônico como propriedade distintiva, mas esquece assim o elemento constitutivo das articulações do Logos: o corpo fono-poético. O dizer e o escrito se sustentam em e com o corpo. Por isso, a escritura como letra morta é arquitraço do corpo vivente que a engendrou. Consequentemente, não há hermenêutica verdadeira se esta se coloca, unicamente, como vivificadora do espírito da letra escrita e não como restituição do corpo atravessado pela hiância do pathos espectral. (NODARI, 2017, p. 16).

Mosé (2001) empresta seu corpo, sua voz e seu próprio sistema de signos e memórias no processo de transcrição do falatório de Stela. Implicam-se no processo muitas das diferenças entre os falares e os contextos de produção de sentidos, especialmente em termos de recepção da obra, pois, entre o público que ouvia Stela (ou mesmo que a leria, caso ela publicasse escrita de próprio punho) e o que lê Viviane, existem diferenças de percepção e de formas de leituras que são determinantes e que perpassam todo um sistema social de assimilação e mesmo de capital simbólico - o que não pode ser ignorado.

Sobre este ser leitor, convém a pertinente proposição de Barthes (2004), em A morte do autor:

Assim se desvenda o ser total da escritura: um texto é feito de escrituras múltiplas, oriundas de várias culturas e que entram umas com as outras em diálogo, em paródia, em contestação; mas há um lugar onde essa multiplicidade se reúne, e esse lugar não é o autor, como se disse até o presente, é o leitor. (BARTHES, 2004, p. 64).

A poética de Stela se aproxima ainda da noção de "biografema" de Barthes (2004), no que diz respeito à relação da escrita com a morte, ou seja, com a retirada de todos os signos de sua individualidade, na medida em que, sendo Stela a autora de suas palavras, devido a um processo de interferência da sua subjetivação pessoal decorrente da internação e da sua condição psíquica, teve de ser intermediada em seu fazer poético e ter suas palavras também re-subjetivadas e recriadas pela escrita de uma segunda autora, de presença e ausência tão oscilantes quanto a primeira. Barthes (2004) escreve: "a escritura é a destruição de toda voz, de toda origem. A escritura é esse neutro, esse composto, esse oblíquo pelo qual foge o nosso sujeito, o branco-e-preto em que vem se perder toda identidade, a começar pela do corpo que escreve" (BARTHES, 2004, p. 57). Partindo-se da proposição de Barthes (2004), podemos considerar o sujeito da escritura (o sujeito que escreve) como um sujeito não real, ou não correspondente ao corpo que fala, a voz de uma identidade que está posta para o sujeito do discurso. A consciência que fala deixa sua unidade subjetiva para se tornar palavra em movimento. Extrapolando-se tal proposição, temos um sujeito que fala e um sujeito que re-fala, um sujeito que poetiza e um sujeito que re-poetiza, estendendo um território já movediço entre a autoria e o texto escrito e duplicando as fronteiras entre o poético/ficcional e o real.

Retomando a questão da identidade que a enunciação de Stela assume por meio da escrita 
de Viviane, e o consequente desenvolvimento de uma identidade autoral híbrida, que ganha livre acesso ao público leitor fora do asilo e se alça como texto artístico de validade reconhecida, percebemos que a função autor é compreendida como uma posição enunciativa, uma característica de seu modo de existência: "um texto anônimo que se lê numa parede da rua terá um redator, mas não um autor. A função autor é, assim, característica do modo de existência, de circulação e de funcionamento de alguns discursos no interior de uma sociedade" (FOUCAULT, 2011, p. 60). Dessa forma, o autor é assinalado e determinado pelos próprios textos, que, por sua vez, podem remeter não a um indivíduo singular, mas a uma grande pluralidade de sujeitos. Além disso, o autor destaca a forma como a Crítica literária tradicionalmente define a noção do autor, partindo de textos e discursos existentes e derivando diretamente da forma como a tradição cristã sempre autenticou ou rejeitou os textos dos quais dispunha. Para Foucault (2011), a crítica moderna utiliza quase as mesmas fórmulas para encontrar e legitimar um autor na obra e "provar o valor de um texto através da santidade do autor" (FOUCAULT, 2011, p. 63). Assim, percebe-se que o texto escrito, ao contrário de um material inerte, vai trazer em si uma série de signos que remetem de volta ao autor, tal como o leitor de Stela só chega ao seu texto em função do reconhecimento e do esforço da já conhecida pesquisadora que lhe traz à luz e, possivelmente da confiança que esse próprio público lhe devota, mas que não necessariamente devotaria à sua criadora de forma isolada.

Esta análise leva a um reexame da noção de sujeito. Segundo Foucault (2011), analisar uma obra do ponto de vista de sua constituição interna e arquitetônica por si já coloca em questão a ideia de um sujeito absoluto e seu papel fundamental. Esse novo exame do conceito de sujeito não quer restaurar uma busca pelo sujeito em sua origem, como formador, mas colocar as questões:

como, segundo que condições e sob que formas alguma coisa como o um sujeito pode aparecer na ordem dos discursos? Que lugar ele pode ocupar em cada tipo de discurso, que funções exercer, e obedecendo a que regras? Tratase, em suma, de retirar do sujeito (ou do seu substituto) seu papel de fundamento originário, e de analisá-lo como uma função variável e complexa do discurso (FOUCAULT, 2011, p. 106).

Deve-se destacar, ainda, o trabalho de Viviane em sua dimensão política e ética, dado que a escolha por materializar a voz de Stela abre um espaço para a escuta de uma voz ensurdecida, considerada não articulável no sistema politicamente constituído da fala, tendo em vista o sujeito que se constitui enquanto dela se utiliza. A voz, em Stela, irrompe de um lugar de desarticulação e subversão política e, no âmbito de sua enunciação, encontra a ordem dos sentidos poéticos não em relação à articulação lógica de sua colocação, mas operando na tessitura da fala e da apreciação dos sentidos, a superfície de um enunciado cuja liberdade Viviane busca cristalizar e rearranjar na sintaxe material gráfica. Dessa forma, o trabalho que a pesquisadora propõe ao leitor leva-o a escutar a voz artística para além do indivíduo, como um evento de enunciação que se tipifica nos limites da discursividade.

Retornando à introdução de Mosé (2001), lemos que, muito da sua justificativa para trazer

Anu. Lit., Florianópolis, v. 25, n. 2, p. 28-46, 2020. ISSNe 2175-7917 
o conteúdo de Stela a público, reside na constatação de que seu discurso pode ultrapassar os limites da instituição psiquiátrica e, como a pesquisadora bem lembra (também recorrendo a Foucault), o significado do ultrapassar de tais limites, especialmente quando se trata da palavra, essa palavra excluída e silenciada pelo estigma da loucura. Justamente de tal estigma emerge a palavra de Stela, que tem em sua voz a expressão da liberdade privada ao corpo.

O discurso que apresentava era de plena racionalidade sobre sua condição, apropriandose da ideia de loucura para convertê-la em experiência poética:

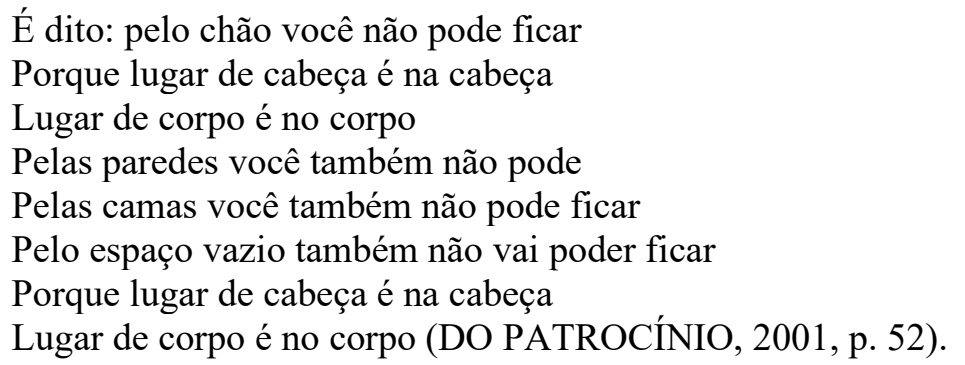

Stela sente em seu corpo o encarceramento e a falta de um lugar no mundo, e se percebe despojada mesmo da ideia de espaço, esvaziando-se enquanto sujeito tal qual um espaço vazio. Os corpos são aprisionados por discursos, da exata forma como o corpo da poeta-enunciadora é banido por um discurso científico-psiquiátrico que silencia a voz do louco por considerá-la a oposição à razão, ela mesma instituída como tal pelo mesmo discurso. Stela demonstra que entende o poder desse discurso e o quanto ele é maior e mais poderoso do que seu corpo e sua voz, que se tornam aprisionados. Dessa forma, nota-se a racionalidade de seu pensamento ao expor a posição de um sujeito poético que reconhece estar banido do socialmente aceito em corpo e voz, um sujeito que examina as instâncias de sua comunicação e a própria falta de interlocução do seu discurso:

Eu já não tenho mais voz

Porque já falei tudo o que tinha que falar

Falo, falo, falo, falo o tempo todo

E é como se eu não tivesse falado nada (DO PATROCÍNIO, 2001, p. 142).

A solidão e o silenciamento são transformados por Stela em performance. Sua palavra poética vem, portanto, do aprisionamento do corpo pelo discurso científico, que condiciona e legitima o poder político capaz de agenciar as políticas de encarceramento dos sujeitos de acordo com suas normas. Segundo Foucault (1984), o poder político da medicina distribui , isola e vigia os indivíduos de modo a constatar o estado de cada um e, dessa forma, estabelecer a sociedade como "um espaço esquadrinhado, dividido, inspecionado, percorrido por um olhar permanente e controlado por um registro, tanto quanto possível completo, de todos os fenômenos" (FOUCAULT, 1984, p. 89). Assim é que a reação ao conceito implementado de doença mental é a exclusão do sujeito doente.

Diante disso, tem-se que o discurso médico perpassa e conforma o discurso poético enunciado por Stela, inundando a vivência e a percepção de si desse sujeito poético trazido à 
luz pelo corpo de Viviane. Por sua vez, se não fosse a leitura própria de Viviane sobre a mesma instituição que aprisionou Stela, uma leitura que se contextualiza em seu tempo, o texto não seria resgatado de suas fitas cassete e não tomariam a forma poética que têm, tampouco a voz de Stela ganharia espaço e interlocução. Consideramos o corpo e a voz de Stela dentro da ideia de que não há uma distinção unívoca entre elas, mas podemos estender essa unicidade também ao trabalho de Viviane, por meio de quem a poesia ganha uma posição equiparável à da lucidez. Os vestígios da poética de Stela se desdobram em matéria e se registram em um corpo escrito perpassado por múltiplas vozes e contextos.

\title{
A voz poética de Stela do Patrocínio na poesia escrita e na leitura
}

Quando pensamos nos corpos que perpassam um poema, ergue-se um tripé em nada tripartido, uma vez que a experiência poética não se dá de forma segmentada. Assim, há o corpo do próprio poema, o do poeta, traduzido em uma poética, e o do leitor. É o corpo do leitor que se relaciona com a voz que emerge do poema, como unidade singular, e como parte de uma corporeidade maior - a poética do poeta. No caso do corpo, e da voz especificamente, de Stela do Patrocínio, a questão se complexifica, tendo em vista que, por sua produção ter sido oral, e posteriormente escrita a partir do trabalho de Viviane Mosé (2001), cabe perguntar como a leitura da poesia escrita se relaciona com esta voz da poeta. Em outras palavras, queremos, agora, investigar até que ponto, pelo processo da escrita, a voz de Stela do Patrocínio (2001) permanece no ato de leitura. Para tanto, acreditamos que seja profícuo realizar este debate pela perspectiva do leitor, dado que é ele que se relaciona com a palavra escrita, seja através da leitura silenciosa ou da em voz alta. E mais: dado que essa relação entre vozes e sujeitos constituídos se dá no plano da escritura, mas igualmente do corpo, entendemos ser relevante centrarmos o nosso olhar no leitor, e não na leitura, em abstrato - uma ideia incorpórea:

\author{
Olha quantos estão comigo \\ Estão sozinhos \\ Estão fingindo que estão sozinhos \\ Pra poder estar comigo (DO PATROCÍNIO, 2001, p. 65).
}

Resolvemos enfocar no leitor como um desejo nosso de que a voz de Stela seja pensada em um espaço povoado e de encontros, dos que estão sozinhos, sem estar. Recorremos, para tanto, a uma imagem: os leitores estão sozinhos, lendo silenciosamente, os poemas de Stela. Fingem estar sozinhos para poderem estar com ela, com sua voz. O poema é lugar de encontro de mundos particulares, de experiências únicas, porque inscritas no corpo - espaço onde o sentido não reina sozinho. A solidão é estado primário e fingimento ao mesmo tempo: fingem estar sozinhos para poder estar com a voz poética, estão com ela porque sozinhos. Voltando à imagem, nosso leitor está sozinho para poder estar com a voz poética, dissimula a solidão, que é antes encontro, com os músculos quase imóveis e apenas os olhos a se moverem com alguma pressa. Estão atravessados - ele e a voz poética de Stela - pela palavra escrita. O corpo físico, a voz que fala os poemas, dilui-se no corpo do poema escrito, e o corpo que o lê já não precisa aguçar a audição ou exercitar as cordas vocais para entrar em contato com ele. Portanto,

Anu. Lit., Florianópolis, v. 25, n. 2, p. 28-46, 2020. ISSNe 2175-7917 
seguindo esta mirada, nos interessa, neste momento, indagar se, e como, a escrita dessa voz de Stela do Patrocínio (2001) afeta este corpo leitor. Ou, dito de outra maneira, até que ponto a escrita interfere na dimensão desta voz poética, enquanto corporeidade que se afirma no espaço, e na relação com a corporeidade com a qual compartilha o mesmo espaço - o leitor e a vida que o poema ganha no ato de leitura.

Começaremos esta discussão trazendo os acúmulos de Hans Gumbrecht (2010), ao discorrer sobre como o pensamento ocidental, e especificamente a modernidade, relegou a um segundo plano a dimensão do corpo, apesar das mudanças teóricas no passar dos séculos. Logo, para o autor, o que persistiu foi uma concepção arraigada do mundo, com suas experiências, como algo a ser interpretado, revelando o seu sentido escondido - o que "quer dizer ir além da superfície material ou penetrar nessa superfície para identificar um sentido (isto é, algo espiritual) que deve estar atrás ou por baixo dela" (GUMBRECHT, 2010, p. 48). Por conseguinte, o interesse reteve-se nessa entidade "espiritual" e incorpórea, que é o sentido - e que nada mais é que uma outra faceta da metafísica ocidental, ao erigir o ser humano como o único detentor deste fundo espiritual, do sentido. Às outras coisas, ao mundo, e ao próprio corpo (antítese do espiritual e da razão iluminada), é relegada uma mudez ensurdecedora: eles não falam e não são ouvidos (GUMBRECHT, 2010). Apesar disso, nós não experienciamos o mundo apenas com o sentido e, em muitas das vezes, somos surpreendidos por um sem par de sensações que nos afetam e que, posteriormente, vamos elaborar racionalmente, interpretandoas e dando sentido a estas.

Por isso, Gumbrecht (2010), em Produção de presença, chama a atenção para esta outra dimensão da experiência humana, a qual chama de presença. O autor, em seu texto, volta inúmeras vezes a elementos importantes para definir o que está denominando como presença, porém dá ênfase "a essa sensação de ser a corporificação de algo" (GUMBRECHT, 2010, p. 167). Ao pensar nessa sensação corporificada, ele atenta para a relação espacial intrínseca a esta, ou seja, “o que é 'presente' para nós [...] está à nossa frente, ao alcance e tangível para nossos corpos" (GUMBRECHT, 2010, p. 38). Por extensão, a produção de presença perpassa a capacidade de produzir uma "tangibilidade (espacial)", através de uma materialidade, percebida nos corpos, produzindo os "efeitos de presença" (GUMBRECHT, 2010, p. 38-39). Para elucidar como se dá esse processo de produção de presença, Gumbrecht (2010) aponta, precisamente, a poesia como exemplo:

A poesia talvez seja o exemplo mais forte da simultaneidade dos efeitos de presença e dos efeitos de sentido - nem o domínio institucional mais opressivo da dimensão hermenêutica poderia reprimir totalmente os efeitos de presença da rima, da aliteração, do verso e da estrofe. [...] as formas poéticas estão numa situação de tensão, numa forma de oscilação com a dimensão do sentido, revelou-se mais um promissor ponto de partida em direção a uma reconceitualização geral da relação entre os efeitos de sentido e os efeitos de presença (GUMBRECHT, 2010, p. 39-40).

Gumbrecht (2010) não advoga pela produção de um tipo de efeito, em detrimento de outro. Pelo contrário, o crítico afirma como estas dimensões convivem juntas e são partícipes 
da experiência humana. Entretanto, sociedades diferentes, ao longo da história e na contemporaneidade, teriam conferido pesos distintos à percepção dos chamados efeitos de presença e de sentido, sendo a nossa calcada, sobretudo, na produção de sentido e de seus efeitos. Por esse motivo, a poesia se apresenta como exemplar, na cultura ocidental, para pensar nos efeitos de presença. O poema performado não é apenas um texto a ser compreendido, mas um corpo que se faz presente no espaço, é tangível pelos seus versos e pelo ritmo, entra em contato com este outro corpo, o do ouvinte/leitor, com o qual divide a espacialidade criada enquanto ele ganha vida. $\mathrm{O}$ assombro, o impacto de um verso final que desorienta por poucos segundos, e o vazio entre o melancólico e o apolíneo, são apenas alguns dos efeitos que um poema pode evocar. Estes oscilam com os efeitos de sentido, com a construção de imagens e de ideias próprias. O poema é um mundo particular e, voltando ao poema de Stela do Patrocínio (2001), é nele que a solidão é, não sendo, sendo fingimento: os efeitos de presença se instalam no corpo, dimensão do indivíduo, mas se dão de maneira povoada, posto que necessita deste encontro - de se estar com o outro.

Ainda, soma-se outro ponto desenvolvido por Gumbrecht (2010), que é acerca da efemeridade dos efeitos de presença, o que em muito se distingue dos efeitos de sentido. Ligada à ideia de performatividade ${ }^{2}$, a produção de presença tem curta duração, posto que, na experiência poética, estes efeitos podem ser sentidos conquanto o poema esteja existindo espacialmente, seja tangível pela sua leitura. Isto é algo fácil de ser ilustrado, se imaginarmos, dentre outros espaços, leituras de poemas em saraus e os diversos efeitos que provocam em quem os ouve. Mesmo que, após o evento, a pessoa saia pensando sobre o sentido de determinados versos, nas imagens que se formaram, é só no momento que os escutou que sentiu um arrepio, ou enojou-se, ou até mesmo os seus olhos marejaram sem encontrarem razão aparente para tanto. De toda maneira, tudo se dá em um lapso, momento irrecuperável. Esta efemeridade, e a nossa tradição epistemológica, fazem com que seja tão desafiador refletir sobre a experiência com a palavra poética a partir da voz - de uma voz que se faz presente, tangível, através de um contato direto com este outro corpo. Ainda assim, acreditamos que este seja um viés rico para ler a poética de Stela do Patrocínio (2001), uma vez que sua poesia se volta para este corpo situado e sitiado, que, não estando sozinho, evoca a palavra como um outro mundo possível, para além do mundo que a encerra.

Não sou eu que gosto de nascer
Eles é que me botam pra nascer todo dia
E sempre que eu morro me ressuscitam
Me encarnam me desencarnam me reencarnam
Me formam em menos de um segundo
Se eu sumir desaparecer eles me procuram onde eu estiver

${ }^{2}$ Os estudos da performance têm acordo sobre não haver um consenso acerca do conceito de performance, o que se liga, por um lado, à pluralidade de manifestações performáticas e, por outro, à própria interdisciplinaridade da área de investigação (TAYLOR, 2013). Ressalvando esta complexidade, Zumthor (2014) aponta para como a performance "está fortemente marcada por sua prática [...] cujo objeto de estudo é uma manifestação cultural lúdica não importa de que ordem (conto, canção, rito, dança), [...] sempre constitutiva de forma" (ZUMTHOR, 2014, p. 33).

Anu. Lit., Florianópolis, v. 25, n. 2, p. 28-46, 2020. ISSNe 2175-7917 
Pra estar olhando pro gás pras paredes pro teto

Ou pra cabeça deles e pro corpo deles (DO PATROCÍNIO, 2001, p. 79).

O poema acima integra a terceira parte do livro, intitulada "Nos gases eu me formei, eu tomei cor", no qual os poemas apontam para esta oscilação entre uma existência fluida em forma, "formada nos gases", e a reafirmação do corpo, este que se pinta de tons diversos no ato de tomar vida. Assim, no poema por nós eleito, o nascer parece imbricado com a existência, e com a reificação desta através dos dias. $\mathrm{O}$ ato, entretanto, não parece se dar por si próprio, pelo contrário, é um outro (são os outros) que a colocam pra nascer todos os dias, dando, à voz, carne - que se encarna, desencarna e volta a reencarnar. E, se podemos aventar um desejo de dissolução desta voz poética, que assume "sumir", os outros parecem ter facilidade de trazê-la de volta, de torná-la presente. Mais, se é necessário procurar por esta voz, dar corpo a ela é algo que ocorre rapidamente, "em menos de um segundo". A existência deste eu poético, então, continua atrelada a um "eles", tendo em vista que os movimentos expressos por essa voz estão diretamente a eles relacionados: trazem-na à vida para que ela veja suas cabeças ou corpos. Este "eles", ainda, não precisa ser necessariamente lido como pessoas, mesmo que sejam corpos. Portanto, a voz poética, ao olhar "pro gás pras paredes pro teto", dirige-se a um outro corpo, que pode ser o hospital e/ou a casa, signos tão recorrentes na poética de Stela do Patrocínio (2001). De toda maneira, ao fazê-la nascer, também "eles" nascem - é a voz poética que os enxerga e enuncia, trazendo-os à cena através de seu próprio corpo, este que morre e volta a viver.

Considerando as dimensões de presença e de sentido como indissociáveis (GUMBRECHT, 2010), entendemos que a poética de Stela do Patrocínio (2001), a exemplo destes versos, evocam em grande medida uma voz que se faz presente, e que reafirma sua existência em um jogo que é, por um lado, de sujeitos e, por outro, de formas, do estado gasoso à concretude dos corpos. A voz poética, então, através dos versos, inscreve-se no próprio espaço do poema, e direciona seu olhar a outras "cabeças e corpos", tão indeterminados quanto a pessoa do discurso escolhida para designá-las. Logo, no poema, a voz produz uma presença de si mesma, mas de um eu atravessado por outros corpos, um "eles" indeterminado, que a engendra sem condicioná-la (eles a têm que procurar). Não nos é possível dizer quais efeitos de presença (GUMBRECHT, 2010) o poema produziu em outros leitores, que não os produzidos em nós mesmas. Por isso, queremos chamar a atenção ao fato de o leitor, ele também com seu peso e medida, mais que se deparar com um emaranhado de sentidos a ser descoberto, um algo mais profundo nestes versos, aludindo à contraparte espiritual da poética de Stela do Patrocínio (2001), depara-se com esta voz que se faz presente, pela afirmação de seu ciclo de vida.

Nesse sentido, a questão das formas na poética da autora nos auxilia na reflexão. Explicando melhor: esta presença da voz poética, com seus efeitos, pode transitar entre estados distintos, sendo ora gasosa e ora tendo a tensão dos músculos, da mesma maneira que ela está inserida em um mundo de formas diversas. Desta maneira, entendemos que a presença que essa voz produz não deve ser compreendida como algo estanque ou arbitrário. Pelo contrário, se imaginarmos o falatório, a expressão oral de Stela, podemos supor que os efeitos de presença 
(GUMBRECHT, 2010) provocados pela performance oral, por ela feita, seriam múltiplos, mas todos provocados por este contato tangível aos sentidos do corpo. Partindo desses elementos, entendemos que a escrita impõe outras questões para a produção dos efeitos de presença. Logo, interrogamo-nos se o registro escrito da poética de Stela do Patrocínio (2001) faria com que a presença da voz poética de seu falatório se perdesse, considerando que esta dimensão tem peso importante na obra. Ou se, em consonância com a própria poética, ela apenas mudaria de estado, mas ainda produzindo efeitos da mesma natureza. Para desenvolver essa discussão, e caminhando para o final de nossas reflexões, gostaríamos de trazer as contribuições de Paul Zumthor (2014, p. 27) "sobre o papel do corpo na leitura e na percepção do literário".

Esta questão é abordada em Performance, recepção, leitura, na qual o autor (ZUMTHOR, 2014) tem uma premissa próxima à de Gumbrecht (2010), sobre como o pensamento ocidental relegou a um segundo plano o corpo e os saberes que dele, e com ele, emergem. Mais especificamente, Zumthor (2014) preocupa-se com este corpo no ato da leitura, tendo em vista que, imersos nesta sociedade voltada à produção de sentidos, nos termos de Gumbrecht (2010), seria preciso, para tanto, romper com "pontos de vista etnocêntricos, e, no caso de poesia ${ }^{3}$, grafocêntricos" (ZUMTHOR, 2014, p. 15). Portanto, não se trataria de falar sobre o corpo na leitura, de maneira abstrata e excluindo a experiência direta com o poema, mas sim de centrar o olhar no corpo do leitor, uma vez que "o corpo é o peso sentido na experiência que faço dos textos" (ZUMTHOR, 2014, p. 27). Assim, se é pela razão que construímos nossas interpretações sobre os textos, é no corpo que a experiência de leitura ganha peso, afetandonos. Por extensão, Zumthor (2014, p. 28) atribui ao prazer, e à percepção sensorial, a "poeticidade (literariedade)" de um texto, para além dos elementos informativos e passíveis de decodificação ou interpretação. É este corpo do leitor, individual, que recebe o texto e o percebe como poético, ao se ver afetado por ele.

Também, Zumthor (2014), ao pensar no corpo do leitor de poesia, remete à ideia de teatralidade, ao refletir sobre como ele, na performance, liga-se ao espaço. A encenação, para o teórico, antes de depender de características físicas obrigatórias, inclusive da presença do ator, caracteriza-se por "uma colocação em cena do sujeito, em relação ao mundo e a seu imaginário" (ZUMTHOR, 2014, p. 44, grifos do autor). Dessa maneira, o espectador, mais que um sujeito passivo, é responsável pela identificação daquele espaço como uma parte outra, apartada do “"real' ambiente, uma fissura pela qual, justamente, introduz-se essa alteridade" (ZUMTHOR, 2014 , p. 44). Isto gera um vínculo entre aqueles que participam deste espaço outro, inclusive os "espectadores", que, antes de apenas se identificarem com o que ocorre, participam e intervêm no que se passa. São parte constituinte deste espaço. Novamente, tal qual em Gumbrecht (2010), a experiência poética atrela-se a uma noção espacial, criando um lugar onde os corpos se fazem

\footnotetext{
${ }^{3}$ É importante ter em vista, para melhor compreensão dos conceitos de Zumthor (2014), a ideia do autor sobre a distinção entre "literatura" e "poesia", aludida na primeira nota de rodapé, e com a qual coadunamos: "A noção de 'literatura' é historicamente demarcada, de pertinência limitada no espaço e no tempo: ela se refere à civilização europeia, entre os séculos XVII ou XVIII e hoje. Eu a distingo claramente da ideia de poesia, que é para mim a de uma arte da linguagem humana, independente de seus modos de concretização e fundamentada nas estruturas antropológicas mais profundas" (ZUMTHOR, 2014, p. 16, grifo do autor).
}

Anu. Lit., Florianópolis, v. 25, n. 2, p. 28-46, 2020. ISSNe 2175-7917 
presentes, com seus pesos próprios. Essa fissura no "ambiente real", por sua vez, faz com que nenhum participante da performance, ou da encenação, possa ser visto apenas como um espectador - tendo em vista que é a sua presença, somada às demais, que cria, justamente, esta abertura à alteridade.

Especificamente sobre as distinções entre a oralidade e a leitura, e entendendo as divergências em torno da questão no campo dos estudiosos de performance, Paul Zumthor (2014) dá uma resposta interessante, ao dizer que "entre a performance - tal qual observamos nas culturas de predominância oral - e nossa leitura solitária e silenciosa, [...] [há,] em vez de corte, uma adaptação progressiva" (ZUMTHOR, 2014, p. 37). Tendo como base seus estudos acerca da oralidade na Idade Média, Zumthor (2014), então, discorre como, apesar de, em aparência, serem dissemelhantes, a performance e a leitura têm em comum o grande traço distintivo, em contraste com as experiências em torno do sentido: o engajamento do corpo sendo que "o que na performance oral pura é realidade experimentada, é, na leitura, da ordem do desejo" (ZUMTHOR, 2014, p. 38). Logo, a distinção estaria, em um primeiro momento, no ato da leitura eliminar as particularidades da oralidade, do "ao vivo", como a unidade e a simultaneidade dos sentidos, o estar situado em cena. Na leitura, estes elementos desapareceriam, sobrando, contudo, um desejo do corpo em restabelecer esta unidade, "por um exercício pessoal, a postura, o ritmo respiratório, pela imaginação" (ZUMTHOR, 2014, p. 66). Esta busca pela restituição do que se perde, por sua vez, está intimamente ligada à procura do prazer, da poeticidade do texto. Tendo em vista esta diferença, mas que parte da mesma vontade, Zumthor (2014) coloca:

Na leitura, essa presença é, por assim dizer, colocada entre parênteses; mas subsiste uma presença invisível, que é a manifestação de um outro, muito forte para que minha adesão a essa voz, a mim assim dirigida por intermédio do escrito, comprometa o conjunto de minhas energias corporais. Entre o consumo, se posso empregar essa palavra, de um texto poético escrito e de um texto transmitido oralmente, a diferença só reside na intensidade da presença (ZUMTHOR, 2014, p. 68).

Assim, entre a oralidade e a escrita, não existiria uma ruptura irreconciliável. Pelo contrário, a presença da voz poética, na leitura do poema escrito, está lá, e é ela que faz com que o leitor vá aderir a esta, dado que, no ato de leitura, em sua completude, conforma-se uma cena, dissociada do espaço cotidiano, onde a busca pelo prazer, pela "poeticidade", permanece. O corpo do leitor, por conseguinte, ainda que imóvel, tem suas energias comprometidas com essa voz, engaja-se sobre o poema, deixa-se ser afetado por ele. E, por extensão, ainda que os membros não se movam, como podemos esperar em performances orais, o desejo persiste, sendo, antes, uma questão de medida, ou, nas palavras de Zumthor (2014, p.68), de "intensidade da presença". Concordando com esta afirmativa, acreditamos que a presença da voz poética de Stela do Patrocínio, ao ser vertida para a escrita por Viviane Mosé (2001), não desaparece. Ela segue evocando este outro, com suas "energias corporais", como se também nos mirasse a cabeça e os corpos. Igualmente, entendemos que isso não significa que não haja descontinuidades com a performance oral de Stela, em vida, mas sim que a diferença esteja 
precisamente na intensidade. Ou seja, se a palavra oral da poeta afetava aos que com ela compartilhavam o espaço do hospital, aqui, o que encontramos, em nós mesmas, enquanto leitoras de seus poemas, é este desejo de fissura, de compartilhar um espaço outro com essa voz, que ganha corpo (encarna, desencarna e reencarna) em nosso ato de leitura:

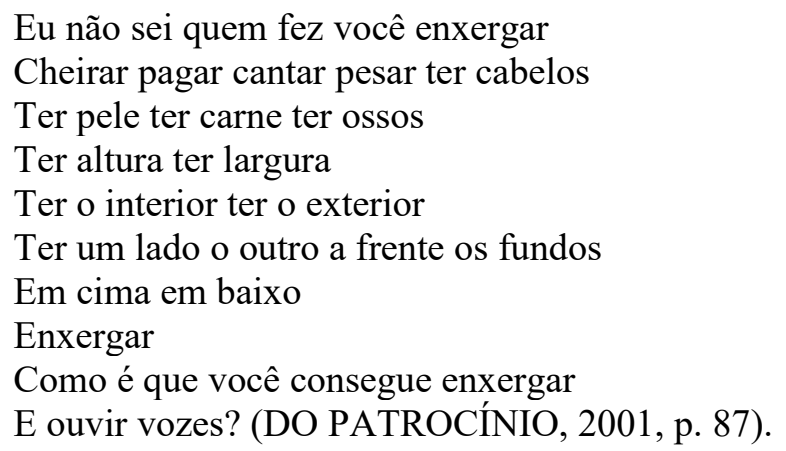

Voltamos ao jogo de sujeitos e de formas. O "eu" se dirige a um você, que parece ser um lugar facilmente ocupável pelo leitor, ou que pode ser um terceiro, e o leitor ser um olhar outro, que constitui a cena que vê, e por extensão se insere. As coisas, ainda assim, não estão dadas, e a voz poética indaga este outro em sua capacidade de enxergar, de colocar seus olhos sobre o mundo. Este outro, lendo os versos que seguem, parece enxergar com o corpo inteiro e, nessa repetição que engendra-o em substância, ao "ter" pele, carne e ossos, faz-se presente em sua própria espacialidade - tal qual uma construção, o interlocutor tem suas medidas, altura e largura, pode ser dividido em interior e exterior, tem frente e fundos. A voz poética, logo, apresenta-se, ou se faz presente, neste ato de mirar um outro, em uma relação de alteridade intensa. E talvez, neste jogo, um dos efeitos de presença (GUMBRECHT, 2010) pela voz poética provocado seja a confusão, marca que ela mesma carrega, por sermos convidados a inclinar nossos corpos, ainda que em desejo (ZUMTHOR, 2014), para este outro.

E enxergar, pela voz, um corpo que não o nosso. Mover nosso imaginário num espaço apartado da realidade, não porque adoecido, mas porque poético, em uma busca incessante pelo prazer e pelas sensações que nos afetam (ZUMTHOR, 2014). Com isso, talvez também não seja descabido dizermos que a voz poética, no poema, não se dirija a apenas um interlocutor, considerando que compartilhamos da mesma cena. Sendo assim, podemos pensar que, ao a voz nos mostrar este outro, ao qual somos convidados a enxergar, nos versos finais, seja a nós mesmas, leitoras, e não leitores hipotéticos, que ela questiona: "Como é que você consegue enxergar / E ouvir vozes?”. Ouvimos a voz poética e somos levadas a enxergar, em uma operação que escapa, ou não se limita, à razão. E mesmo se esta voz não se dirigir a ninguém, mas instalar-se como um acontecimento em pátio aberto, nós todos que a ouvimos, e por isso procuramos ver o outro, não seremos menos afetados - mediremos a nós mesmos por este outro que é confusão e desejo. Logo, para finalizar esta breve discussão, acreditamos que os efeitos que a presença da voz poética de Stela do Patrocínio não desaparecem com a transposição de sua poesia para a escrita, feita por Viviane Mosé (2001), e nem deixam de reverberar nos corpos que são por ela atingidos. A voz de Stela evoca-nos a este espaço, ainda que imóveis, em leitura 
silenciosa, e estamos de pronto à sua frente, enxergando e sendo enxergados. Uma voz que canta, que se afirma, e faz-se ouvir.

\section{Algumas palavras finais}

Como dissemos no início do texto, nosso interesse, com esse trabalho, foi investigar a persistência da voz de Stela do Patrocínio no processo de transposição de sua poética, originalmente oral, para a poesia escrita. Para tanto, sem desconsiderar o contexto de feitura da obra, mas também sem nos focarmos na questão psiquiátrica que daí advinha, debruçamo-nos na constituição dessa voz por dois vieses: pela constituição da autoria (FOUCAULT, 2009; 2011) e pelo papel do leitor no acesso e contato com esta voz poética (GUMBRECHT, 2010; ZUMTHOR, 2014). Com isso, encontramos respostas que apontam para lados que, se não em tudo coincidentes, encontram-se no fato de, apesar de todas as descontinuidades entre a oralidade e a escrita, não ser possível dizer que, com a passagem para a escrita, operada por Mosé (2001), a voz poética de Stela desapareça. Pelo contrário, o que constatamos é que esta se refrata, seja por meio de uma noção de escritura, que recoloca, e questiona, o lugar do enunciador, e por extensão do sujeito, em si (e em especial em um contexto psiquiátrico, para além das bordas do que se convencional chamar de normalidade, ou sanidade); ou por uma teoria que recoloque o leitor, com seu peso medido na experiência poética, em cena, e, com isso, defronte-se com a voz poética que enuncia e que, por extensão, produz presença.

Dessa forma, por um lado, acreditamos que, através da leitura da poética presente na obra (DO PATROCÍNIO, 2001), pudemos levantar elementos interessantes para a crítica literária de poesia contemporânea, e especificamente da obra de Stela do Patrocínio. Por outro, entendemos que, ao abordarmos poéticas que fragmentem a noção de sujeito, expomo-nos a pensar em categorias aparentemente consolidadas na área, tendo em vista sua revisitação periódica. A poética de Stela do Patrocínio (2001), ainda, ao não se encaixar nos padrões epistemológicos ocidentais, abre-nos a um sem par de possibilidades, um sem par de vozes. Ao nos defrontarmos com estas, mais do que investir contra, entendemos que é papel da disciplina aprender a ouvilas, com seu ritmo próprio, e, diante de sua presença, seu corpo único, fazer com que nos deparemos com a nossa solidão, existencial, textual e epistemológica - estar sozinho na presença de um outro. Portanto, não achamos que se trata de fazer uma leitura correta, ou equivocada, da poética. Pelo contrário, nesse caso, nosso desejo foi, através de um fio teórico, fazer com que a própria voz poética de Stela do Patrocínio, encalacrada pela palavra escrita, pudesse vir à tona. Como um grito abafado ou uma ação coordenada, calculada entre a tensão dos tempos nas catástrofes pessoais: uma voz que irrompe a escritura e atinge o corpo, para se perder no eco, na efemeridade da experiência poética, ou na perenidade que a escritura pressupõe, ainda que movediça - como o é na poesia, mas também aqui, quando tentamos nos fazer presentes, leitoras de Stela do Patrocínio (2001) que somos. Ainda que sem ouvi-la em voz alta, silenciosas e em meio a um pátio aberto, seguimos a sua voz. 


\section{Referências}

AQUINO, Ricardo. Estrela. In: DO PATROCÍNIO, Stela. Reino dos bichos e dos animais é meu nome. Organização de Viviane Mosé. Rio de Janeiro: Azougue Editorial, 2001, p. 13-17.

BARTHES, Roland. A morte do autor. In: BARTHES, Roland. O rumor da língua. Trad. de Mário Laranjeira. São Paulo: Martins Fontes, 2004, p. 57-64.

DO PATROCÍNIO, Stela. Reino dos bichos e dos animais é meu nome. Organização de Viviane Mosé. Rio de Janeiro: Azougue Editorial, 2001.

FOUCAULT, Michel. Microfísica do poder. Tradução e organização de Roberto Machado. Rio de Janeiro: Edições Graal, 1984.

FOUCAULT, Michel. Estética: literatura e pintura, música e cinema. Trad. de Inês Autran Dourado Barbosa. Rio de Janeiro: Forense Universitária, 2009.

FOUCAULT, Michel. O que é um autor? Trad. de Antônio Fernando Cascais e Eduardo Cordeiro. In: QUEIROZ, Sônia (Org.). O que é um autor?, de Michel Foucault. Duas traduções para o português. Belo Horizonte: FALE/UFMG, 2011, p. 51-82.

GUMBRECHT, Hans Ulrich. Produção de presença: o que o sentido não consegue transmitir. Rio de Janeiro: Contraponto; Ed. PUC-Rio, 2010.

MOSÉ, Viviane. Apresentação. In: DO PATROCÍNIO, Stela. Reino dos bichos e dos animais é meu nome. Organização de Viviane Mosé. Rio de Janeiro: Azougue Editorial, 2001, p. 19-43.

NODARI, Alexandre. Tradizer. In: FLORES, Guilherme Gontijo; GONÇALVES, Rodrigo Tadeu. Algo infiel. Corpo, performance, tradução. Desterro: Cultura e Barbárie, 2017, p. 13-16.

TAYLOR, Diana. O arquivo e o repertório - Performance e memória cultural nas Américas. Belo Horizonte: Ed. UFMG, 2013.

ZUMTHOR, Paul. Performance, recepção, leitura. São Paulo: Cosac Naify, 2014.

\section{NOTAS DE AUTORIA}

Marianna Ilgenfritz Daudt (maridaudt@gmail.com) é doutoranda no Programa de PósGraduação em Letras da Universidade Federal do Rio Grande do Sul (UFRGS) em Estudos de Literatura / Teoria, Crítica e Comparatismo Literário. Bolsista CAPES. Mestra em Letras Teoria, Crítica e Comparatismo Literário pela UFRGS. Formada em Letras - Bacharelado português/alemão pela Universidade Federal do Rio Grande do Sul.

Fernanda Vivacqua (fernandavivacquaa@gmail.com) é doutoranda em Letras, pelo Programa de Pós-Graduação em Letras da Universidade Federal do Rio Grande do Sul, na área de concentração: Estudos literários, e linha de pesquisa: Teoria, crítica e comparatismo (2019atual). Mestra em Letras - Estudos literários, pelo Programa de Pós-Graduação em Letras Estudos literários da Universidade Federal de Juiz de Fora (2017-2019), universidade onde se graduou em Letras - Língua Portuguesa e suas respectivas literaturas (2012-2016).

\section{Como citar esse artigo de acordo com as normas da revista}


DAUDT, Marianna Ilgenfritz; VIVACQUA, Fernanda. A persistência da voz poética em Stela do Patrocínio: entre a oralidade e a escrita. Anuário de Literatura, Florianópolis, v. 25, n. 2, p. 28-46, 2020.

\section{Contribuição de autoria}

Marianna Ilgenfritz Daudt: Concepção, seleção e análise de corpus, elaboração, redação de manuscrito, redação final, análise teórico-crítica a partir do corpus.

Fernanda Vivacqua: Concepção, seleção e análise de corpus, elaboração, redação de manuscrito, redação final, análise teórico-crítica a partir do corpus.

\section{Financiamento}

O presente trabalho foi realizado com apoio da Coordenação de Aperfeiçoamento de Pessoal de Nível Superior - Brasil (CAPES) - Código 001.

\section{Consentimento de uso de imagem}

Não se aplica.

\section{Aprovação de comitê de ética em pesquisa}

Não se aplica.

\section{Licença de uso}

Este artigo está licenciado sob a Licença Creative Commons CC-BY. Com essa licença você pode compartilhar, adaptar, criar para qualquer fim, desde que atribua a autoria da obra.

\section{Histórico}

Recebido em: 25/03/2020

Revisões requeridas em: 25/06/2020

Aprovado em: 17/07/2020

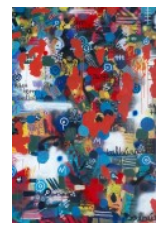

